\title{
INVESTIGAÇÕES STRICTO SENSU SOBRE A FORMAÇÃO DE PROFESSORES NO QUE TANGE AOS NÚMEROS DECIMAIS:

\author{
teor e referências
}

\author{
Thiago Beirigo Lopes' \\ Pedro Franco de Sá2
}

\begin{abstract}
RESUMO
Os números decimais integram o cotidiano em experiências comuns como medir, contar, comparar e realizar operações aritméticas. Como exemplo, nos sistemas de medida e monetário adotados em âmbito nacional, números decimais são amplamente presentes. No âmbito escolar, mais especificamente na formação de professores que ensinam matemática, são realizadas pesquisas stricto sensu que envolvem os números decimais. Diante disso, a investigação realizada teve como objetivo analisar teses ou dissertações sobre números decimais, teor e referências, que tiveram como foco a formação do professor que ensina matemática. Foi possível realizar um estudo sobre as teses ou dissertações que cumpriam o escopo, bem como de suas palavras-chave e das publicações utilizadas como aporte teórico, resultando em um mapeamento dessas pesquisas, com o qual foi possível constatar a variedade de objetivos, metodologias e resultados. Ainda, e mais profundamente, foram analisados os principais pressupostos teóricos que embasaram as investigações de mestrado ou doutorado por meio de suas referências, considerando ano, tipo, autor e título dessas.
\end{abstract}

Palavras-chave: Números decimais. Formação de professores. Bases epistemológicas.

\section{RESEARCH STRICT SENSU ON THE FORMATION OF TEACHERS IN WHICH THE DECIMAL NUMBERS: content and references}

\begin{abstract}
Decimal numbers integrate everyday into common experiences such as measuring, counting, comparing, and performing arithmetic operations. As an example, in the

1 Doutorando em Educação em Ciência e Matemática. Programa de Pós-Graduação em Educação em Ciências e Matemática (PPGECEM) da Universidade Federal de Mato Grosso (UFMT). Orcid iD: http://orcid.org/000-0002-9409-6140. E-mail: thiagobeirigolopes@yahoo.com.br

2 Doutor em Educação (UFRN). Professor do Programa de Pós-Graduação em Educação em Ciências e Matemática (PPGECEM) da Universidade Federal de Mato Grosso (UFMT). Orcid iD: http://orcid.org/000-0002-8986-2787. E-mail: pedro.franco.sa@gmail.com
\end{abstract}

Revista Êxitos, Santarém/PA, Vol. 9, № 4, p. 606 - 634, Out/Dez 2019. 
measurement and monetary systems adopted at the national level, decimal numbers are widely present. In the school context, more specifically in the training of teachers who teach mathematics, stricto sensu researches involving the decimal numbers are carried out. The aim of this research was to analyze theses or dissertations on decimal numbers, content and references, which focused on the formation of the teacher who teaches mathematics. To do so, a mapping of these researches and analyzes was carried out to ponder the references that supported their respective investigations. It was possible to carry out a study on the theses or dissertations that fulfilled the scope, the keywords and the publications used as references. A mapping was carried out and the variety of objectives, methodologies and results were verified. Still, and more deeply, analyzed the main theoretical assumptions that supported the master's or doctoral research through their references. In what were considered year, type, author and title of these references.

Keywords: Decimal numbers. Teacher training. Epistemological bases.

\section{INVESTIGACIONES STRICTO SENSU SOBRE LA FORMACIÓN DE PROFESORES EN QUE TANGE LOS NÚMEROS DECIMALES: contenido y referencias}

\section{RESUMEN}

Los números decimales integran lo cotidiano en experiencias comunes como medir, contar, comparar y realizar operaciones aritméticas. Como ejemplo, en los sistemas de medida y monetario adoptados a nivel nacional, los números decimales son ampliamente presentes. En el ámbito escolar, más específicamente en la formación de profesores que enseñan matemáticas, se realizan investigaciones stricto sensu que involucra los números decimales. La investigación realizada tuvo como objetivo analizar tesis o disertaciones sobre números decimales, tenor y referencias, que tuvieron como foco la formación del profesor que enseña matemáticas. Para ello, se realizó un mapeamiento de esas investigaciones y análisis para ponderar sobre las referencias que ampararon sus respectivas investigaciones. Se pudo realizar un estudio sobre las tesis o disertaciones que cumplían el alcance, las palabras clave y las publicaciones utilizadas como referencias. Se realizó un mapeo y constatado la variedad de objetivos, metodologías y resultados. Aún, y más profundamente, analizados los principales presupuestos teóricos que basaron las investigaciones de maestría o doctorado por medio de sus referencias. En el que se consideraron año, tipo, autor y título de dichas referencias.

Palabras clave: Números decimales. Formación de profesores. Bases epistemológicas.

\section{INTRODUÇÃO}

Na vida moderna, os números decimais fazem parte do cotidiano, no que tange às experiências comuns como medir, contar, comparar e realizar operações. No sistema de medida e no sistema monetário que são adotados 
em abrangência nacional, os números decimais estão amplamente presentes.

No âmbito escolar, os números decimais têm destaque também devido estarem em evidência nos parâmetros que regem o ensino nos anos iniciais do ensino fundamental e nos livros didáticos utilizados. Pesquisas em nível stricto sensu foram e vêm sendo realizadas sobre a aprendizagem desses números. Mas, referente à formação de professores que ensinam matemática, esse artigo traz os frutos da investigação realizada que teve como objetivo analisar teses ou dissertações sobre números decimais, teor e referências, que tiveram como foco a formação do professor que ensina matemática.

Para tanto, foi realizado um mapeamento dessas pesquisas, com destaque para seus títulos, autores, orientadores, instituição e Programa de Pós-Graduação (PPG) ao qual cada uma está vinculada. Posteriormente são realizadas métricas para ponderar sobre as bases epistemológicas que ampararam suas respectivas investigações, com alicerce em informações que foram extraídas das palavras-chave e das publicações utilizadas como referência.

Em apresentação dos resultados de investigação, este trabalho compreende, além desta introdução, mais seis seções. Na próxima seção, um referencial teórico em que são explicitados os embasamentos que subsidiam a investigação. Posteriormente, são explicitados os procedimentos metodológicos que orientaram a investigação. Em seguida, são registrados e analisados os resultados da pesquisa em termos do mapeamento da produção em teses ou dissertações e estudo das referências nelas utilizadas. Os resultados estão distribuídos em três seções, a primeira seção trazendo um mapeamento das teses ou dissertações, foco da investigação; a segunda seção indicando o teor; e a terceira seção fazendo o estudo e análise sobre as referências utilizadas com foco no autor, publicação, tipo de publicação e ano. Por fim, na última seção, são consignadas as considerações e ponderações sobre a relevância e as limitações da investigação realizada. 


\section{REFERENCIAL TEÓRICO}

No campo das publicações científicas, as palavras-chave mostram (ou pelo menos deveriam mostrar) a abrangência do assunto investigado e os seus conceitos principais, ainda são bastante úteis para a indexação em bases de pesquisa ou para categorização da publicação. De acordo com Miguéis et al. (2013, p. 112) "[...] a investigação sobre a importância e caraterísticas das palavras-chave tem incidido sobre vários aspectos", entre os quais podem ser destacados: a eficiência na disponibilização de informação e o uso para buscas automática a partir de diferentes algoritmos por meio dos metadados 3 .

Outra característica de trabalhos científicos que tem ganhado importância refere-se ao meio em que são publicados. A publicação, de acordo com Macias-Chapula (1998, p. 137), "[...] reflete os produtos da ciência, medidos pela contagem dos trabalhos e pelo tipo de documentos (livros, artigos, publicações científicas, relatórios etc.)". Ainda segundo o autor, a dinâmica da comunicação científica resultante de pesquisas pode ser monitorada e sua tendência delineada ao longo do tempo.

Nos resultados da investigação realizada por Mueller (2005) fica evidente que pesquisadores de diferentes áreas têm preferências próprias, distintas entre si, e que os órgãos reguladores dos PPG estão interferindo paulatinamente nesse quadro, principalmente com o estabelecimento de critérios de avaliação.

Sobre as referências elencadas nas publicações resultantes de investigações, Loiola e Bastos (2003) indicam que os levantamentos desta natureza são relevantes para subsidiar incentivo à reflexão pelos próprios pesquisadores, em relação aos desafios e limites que circundam sua prática. Ainda segundo os autores, assim há a possibilidade de exploração de quadros teóricos que deram suporte às pesquisas estudadas, tanto na origem das referências utilizadas, como no aprofundamento dos objetos investigados.

3 Um componente de um metadado deve indicar do que se trata aquele dado, que geralmente é uma informação inteligível por um "robô virtual". 
Segundo Rodrigues (1982, p. 36), as citações (referências) utilizadas na elaboração de um documento estabelecem relações entre um documento e outro, uma pesquisa e outra, uma ideia e outra, ou seja, "[...] evidenciam elos entre indivíduos, instituições e áreas de pesquisa". A autora supracitada destaca que o índice de citação utilizados em bases de indexação, como ISI, Scopus, Scielo e Google Acadêmico, tem elevado as citações bibliográficas a uma posição de considerável importância, que se revela como informativo sobre o que já foi publicado sobre o assunto e mostra as inter-relações uma publicação citada e o citante.

Vergara e Pinto (2001) acreditam que referências bibliográficas utilizadas por um autor destacam os seguintes pontos: 1) são seus suportes teóricos de argumentação; 2) revelam suas preocupações, preferências e suposições; 3) podem ser indicadores da importância por ele atribuída à produção científica e ao contexto; e 4) podem ser indicadores do seu condicionamento por outras culturas.

Já há algum tempo, Betero, Caldas e Wood Jr (1999) indicam que o tema de referências tem sido tratado por pesquisadores que têm focalizado a classificação da produção, em termos epistemológicos, bem como o referencial teórico utilizado por autores locais e a aplicação teórica e prática da pesquisa produzida.

\section{PROCEDIMENTOS METODOLÓGICOS}

A pesquisa realizada se trata de um levantamento bibliográfico com embasamento no conjunto das técnicas da análise de conteúdo, segundo Bardin (2011, p. 153), a análise por categoria, a qual tem a cronológica como a mais antiga e mais utilizada, "[...] funciona por operações de desmembramento do texto em unidades, em categorias segundo reagrupamentos analógicos".

Ainda na concepção de Bardin (2011, p. 109), uma medida frequencial simples é firmada no seguinte pressuposto: "[...] a aparição de um item de sentido ou de expressão, será tanto mais significativa - em relação ao que procura atingir na descrição ou na interpretação da 
realidade visada - quanto mais esta frequência se repetir". Desse modo, uma maior regularidade quantitativa da frequência se refere ao que é considerado como mais significativo.

Com base nesse pressuposto metodológico, no primeiro semestre de 2017 foi feito um levantamento de dados no Banco de Teses e Dissertações mantido pela Coordenação de Aperfeiçoamento de Pessoal de Nível Superior (CAPES) em que foi utilizada a palavra-chave "decimais" para encontrar as publicações de resultados das investigações que seriam foco desse estudo. Foi utilizada somente uma palavra-chave por se ter a intenção de poder verificar cada uma de todas as publicações que fazem referência a esse termo. Com esse parâmetro, foram mostrados 199 trabalhos, havendo então a necessidade de refinamento nos parâmetros de busca. Analisou-se separadamente as teses ou dissertações pela Grande Área Conhecimento, então, devido não ter trabalhos que cumprem o escopo da pesquisa, foram suprimidos os parâmetros: Ciências agrárias; Ciências Biológicas; Ciências da Saúde; Ciências sociais aplicadas; e Engenharias. Ao permanecerem os parâmetros: Ciências exatas e da terra; Ciências humanas; e Multidisciplinar, a quantidade diminuiu para 104 trabalhos mostrados.

Em outro momento, foi utilizada a palavra-chave de pesquisa "decimal", como complementar a procura inicialmente realizada. O motivo de utilizar somente uma palavra-chave é o mesmo da primeira consulta. Com esse parâmetro, foram mostrados 306 trabalhos e novamente foi necessário o refinamento nos parâmetros de busca pelos mesmos critérios anteriormente citados, em que tiveram sua quantidade diminuída para 161 trabalhos.

Ainda houve a necessidade de analisar os trabalhos um por um, até se chegar à quantidade de 23 na primeira busca e 3 trabalhos novos na segunda busca, totalizando 26 publicações que investigaram sobre números decimais. Desses 26 trabalhos, foram verificados os que envolviam formação de professores que ensinam matemática e encontrados 11, posteriormente divididos em duas classificações. Então, as seguintes classificações são:

1) Estudos que apresentaram propostas de ensino; e 
2) Estudos que investigaram os saberes e práticas dos professores.

Apesar da primeira publicação que investigou sobre números decimais ser datada de 1995, somente em 2008 há publicação sobre formação de professores que ensinam matemática. Desse modo, o recorte temporal possível foi de 2008 a 2015.

Em posse das 11 publicações, foi realizado um mapeamento que levou em consideração se o trabalho era oriundo de orientação de mestrado ou doutorado, a classificação conforme as duas indicadas anteriormente, título e autor. Também foram mapeados o orientador, a instituição e o PPG ao qual o autor estava vinculado. Posteriormente, foi realizado um estudo em que são apresentados os principais itens dessas teses ou dissertações, que são: objetivo(s) da pesquisa, procedimento metodológico utilizado e resultados obtidos. Foi também efetivado um levantamento das palavraschave indicadas em cada trabalho para ver quais objetos estão mais frequentemente envolvidos nas pesquisas, isso com o intuito de traçar seu panorama epistemológico.

Também foram realizados levantamentos quantitativos nas referências utilizadas nas teses ou dissertações, em que foram contabilizados 656 itens no total, média aritmética de 59,6 referências. Essas referências foram contabilizadas em planilhas eletrônicas para que não houvesse repetição ou falta de itens na contagem. Posteriormente foram analisados cada item das referências, a saber:

- Tipos e período de publicação: são levantados os tipos de publicação (livro, artigo, tese, outros) em relação ao ano/período em que foram publicados. Essa seção busca analisar se os tipos de publicação consultados se alteraram com o tempo;

- Autores das publicações de referência: são levantados até três autores de cada tese ou dissertação, inclusive autores coorporativos. Essa seção busca analisar se há autores que sejam referência no campo de estudo e qual sua área de atuação prioritária; e

- Títulos das publicações consultadas: são levantadas as publicações que serviram de referência para as investigações de mestrado ou doutorado 
estudadas. Essa seção busca analisar quais são as bases em que essas investigações foram ancoradas, com vista a traçar um panorama epistemológico com base nas referências que as sustentam.

Em todas as seções descritas nos resultados, são realizados levantamentos quantitativos com a realização de inferência sobre os dados obtidos.

\section{SOBRE O MAPEAMENTO DAS TESES OU DISSERTAÇÕES}

No mapeamento das dissertações e teses que investigaram sobre números decimais e tiveram foco na formação do professor que ensina matemática, foi identificado um total de 11 publicações, 2 teses e 9 dissertações, que estão dispostas no QUADRO IQUADRO 1, classificados por:

- Nível: refere-se como dissertação (D) ou tese (T);

- Classificação (Clas.): refere-se às classificações 1 e 2 citadas na seção de procedimentos metodológicos;

- Título: refere-se ao título do trabalho;

- Ano: refere-se ao ano em que foi apresentada ou defendida a pesquisa;

- Autor: refere-se a autor (orientado) da pesquisa;

- Orientador: refere-se ao pesquisador que orientou a pesquisa;

- Instituição: refere-se à instituição em que o PPG está vinculado; e

- PPG: refere-se ao programa em que a publicação está vinculada.

QUADRO 1 - Ralação das 11 teses ou dissertações encontradas, com seus respectivos dados

\begin{tabular}{|c|c|c|c|c|c|c|c|}
\hline Nível & Cla. & Título & Ano & Autor & Orientador & Instituição & PPG \\
\hline D & 1 & $\begin{array}{l}\text { Uma sequência didática } \\
\text { para o ensino das } \\
\text { operações com os números } \\
\text { decimais }\end{array}$ & 2008 & $\begin{array}{l}\text { Rosineide } \\
\text { de Sousa } \\
\text { Jucá }\end{array}$ & $\begin{array}{l}\text { Pedro } \\
\text { Franco de } \\
\text { Sá }\end{array}$ & UEPA & Educação \\
\hline D & 2 & $\begin{array}{l}\text { Procedimentos Didáticos } \\
\text { Relativos ao Ensino de } \\
\text { Números Racionais em } \\
\text { Nível de Sexto e Sétimo } \\
\text { Anos do Ensino } \\
\text { Fundamental }\end{array}$ & 2009 & $\begin{array}{l}\text { Irio Valdir } \\
\text { Kichow }\end{array}$ & $\begin{array}{l}\text { Luiz Carlos } \\
\text { Pais }\end{array}$ & UFMS & $\begin{array}{l}\text { Educação } \\
\text { Matemática }\end{array}$ \\
\hline D & 2 & $\begin{array}{l}\text { Números decimais na } \\
\text { escola fundamental: } \\
\text { interações entre os }\end{array}$ & 2009 & $\begin{array}{l}\text { Anelisa } \\
\text { Kisielewski } \\
\text { Esteves }\end{array}$ & $\begin{array}{l}\text { Neusa } \\
\text { Maria } \\
\text { Marques de }\end{array}$ & UFMS & $\begin{array}{l}\text { Educação } \\
\text { Matemática }\end{array}$ \\
\hline
\end{tabular}




\begin{tabular}{|c|c|c|c|c|c|c|c|}
\hline & & $\begin{array}{l}\text { conhecimentos de um } \\
\text { grupo de professores e a } \\
\text { relação com sua prática } \\
\text { pedagógica }\end{array}$ & & & Souza & & \\
\hline D & 2 & $\begin{array}{l}\text { Uma análise de reflexões e } \\
\text { de conhecimentos } \\
\text { construídos e mobilizados } \\
\text { por um grupo de } \\
\text { professores no ensino de } \\
\text { números decimais para o } \\
\text { sexto ano do ensino } \\
\text { fundamental }\end{array}$ & 2011 & $\begin{array}{l}\text { Adriana } \\
\text { Fatima de } \\
\text { Souza } \\
\text { Miola }\end{array}$ & $\begin{array}{l}\text { Patrícia } \\
\text { Sandalo } \\
\text { Pereira }\end{array}$ & UFMS & $\begin{array}{l}\text { Educação } \\
\text { Matemática }\end{array}$ \\
\hline D & 2 & $\begin{array}{l}\text { Ensino e Aprendizagem das } \\
\text { Operações com Números } \\
\text { Decimais através da } \\
\text { Resolução de problemas } \\
\text { no Ensino Fundamental }\end{array}$ & 2011 & $\begin{array}{l}\text { Lívia da } \\
\text { Cás } \\
\text { Pereira }\end{array}$ & $\begin{array}{l}\text { Silvia Maria } \\
\text { de Aguiar } \\
\text { Isaia }\end{array}$ & UniFra & $\begin{array}{l}\text { Ensino de } \\
\text { Matemática }\end{array}$ \\
\hline$T$ & 1 & $\begin{array}{l}\text { Ensino e aprendizagem do } \\
\text { número racional positivo na } \\
\text { forma decimal: análise de } \\
\text { uma experiência de } \\
\text { inversão curricular }\end{array}$ & 2012 & $\begin{array}{l}\text { Lady } \\
\text { Sakay }\end{array}$ & $\begin{array}{l}\text { Cristiano } \\
\text { Alberto } \\
\text { Muniz }\end{array}$ & UNB & Educação \\
\hline D & 2 & $\begin{array}{l}\text { Os números em sua } \\
\text { representação decimal: de } \\
\text { Euclides Roxo ao } \\
\text { Movimento da Matemática } \\
\text { Moderna }\end{array}$ & 2014 & $\begin{array}{l}\text { Roberta } \\
\text { Bertignolo } \\
\text { Alves }\end{array}$ & $\begin{array}{l}\text { Aparecida } \\
\text { Rodrigues } \\
\text { Silva Duarte }\end{array}$ & $\begin{array}{l}\text { Universi- } \\
\text { dade } \\
\text { Anhan- } \\
\text { guera }\end{array}$ & $\begin{array}{l}\text { Educação } \\
\text { Matemática }\end{array}$ \\
\hline D & 2 & $\begin{array}{l}\text { Relações entre professores } \\
\text { e materiais curriculares no } \\
\text { ensino de números naturais } \\
\text { e sistema de numeração } \\
\text { decimal }\end{array}$ & 2014 & $\begin{array}{l}\text { Silvana } \\
\text { Ferreira } \\
\text { de Lima }\end{array}$ & $\begin{array}{l}\text { Celia Maria } \\
\text { Carolino } \\
\text { Pires }\end{array}$ & PUC/SP & $\begin{array}{l}\text { Educação } \\
\text { Matemática }\end{array}$ \\
\hline D & 1 & $\begin{array}{l}\text { Números decimais e o } \\
\text { tema transversal trabalho e } \\
\text { consumo: um experimento } \\
\text { utilizando uma sequência } \\
\text { didática eletrônica }\end{array}$ & 2015 & $\begin{array}{l}\text { Rosana } \\
\text { Pinheiro } \\
\text { Fiuza }\end{array}$ & $\begin{array}{l}\text { Claudia } \\
\text { Lisete } \\
\text { Oliveira } \\
\text { Groenwald }\end{array}$ & ULBRA & $\begin{array}{c}\text { Ensino de } \\
\text { Ciências e } \\
\text { Matemática }\end{array}$ \\
\hline$T$ & 2 & $\begin{array}{l}\text { Conhecimentos de } \\
\text { professores dos anos iniciais } \\
\text { para o ensino dos números } \\
\text { racionais em sua } \\
\text { representação decimal }\end{array}$ & 2015 & $\begin{array}{l}\text { Norma } \\
\text { Kerches } \\
\text { de } \\
\text { Oliveira } \\
\text { Rogeri }\end{array}$ & $\begin{array}{l}\text { Ruy César } \\
\text { Pietropaolo }\end{array}$ & $\begin{array}{l}\text { Universi- } \\
\text { dade } \\
\text { Anhan- } \\
\text { guera }\end{array}$ & $\begin{array}{l}\text { Educação } \\
\text { Matemática }\end{array}$ \\
\hline$D$ & 1 & $\begin{array}{l}\text { Formalização dos } \\
\text { Conjuntos Numéricos: } \\
\text { contribuição para o ensino } \\
\text { de frações e números } \\
\text { decimais }\end{array}$ & 2015 & $\begin{array}{l}\text { Cleber } \\
\text { Alves } \\
\text { Côrtes }\end{array}$ & $\begin{array}{l}\text { Parham } \\
\text { Salehyan }\end{array}$ & UNESP & $\begin{array}{c}\text { Matemática } \\
\text { em Rede } \\
\text { Nacional }\end{array}$ \\
\hline
\end{tabular}

Fonte: Repositórios das instituições onde os trabalhos foram publicados, baseado em Lopes e Sá (2018).

Em uma perspectiva mais panorâmica, verificou-se que, das 11 pesquisas, a Universidade Federal de Mato Grosso do Sul (UFMS) teve 3 contabilizadas, sendo a instituição com maior quantidade. Também pode-se 
perceber que não há predominância institucional nas pesquisas, visto que há um total de 8 instituições espalhadas por vários lugares do território nacional.

No que diz respeito à questão temporal, pode ser percebido que as pesquisas que envolvem o escopo da investigação realizada são recentes. A primeira sobre números decimais disponível no Banco de Teses e Dissertações da CAPES é a de Porto (1995), no entanto a que é sobre formação de professor nessa área é a de Jucá (2008). Conforme a Tabela 1, pode ser verificada um crescente e não linear aumento na quantidade de investigações em nível de stricto sensu em relação ao estudo sobre ensino ou aprendizagem de números decimais.

TABELA 1 - Frequência de teses ou dissertações em relação ao ano de publicação

\begin{tabular}{cc}
\hline Ano & Frequência \\
\hline 2008 & 1 \\
2009 & 2 \\
2010 & 0 \\
2011 & 2 \\
2012 & 1 \\
2013 & 0 \\
2014 & 2 \\
2015 & 3 \\
\hline Total & 11 \\
\hline
\end{tabular}

Fonte: Repositórios das instituições onde os trabalhos foram publicados, baseado em Lopes e Sá (2018).

Quanto ao PPG que o autor de cada pesquisa está vinculado, a maior frequência de pesquisas foi de PPG de Educação Matemática, com uma quantidade de 6 trabalhos, conforme Tabela 2.

TABELA 2 - Quantidade de teses ou dissertações por PPG

\begin{tabular}{cc}
\hline PPG & Frequência \\
\hline Educação Matemática & 6 \\
Ensino de Matemática & um \\
Educação & 2
\end{tabular}


Ensino de Ciências e Matemática $\quad 1$

Matemática em Rede Nacional

Total

Fonte: Repositórios das instituições onde os trabalhos foram publicados, baseado em Lopes e Sá (2018).

Em relação às classificações, as teses ou dissertações se enquadram da seguinte forma:

1) Estudos que apresentaram propostas de ensino;

Foram classificadas 4 pesquisas, que são: Jucá (2008), Sakay (2012), Fiuza (2015) e Côrtes (2015). Todos de PPG e instituições diferentes, com a única ocorrência comum sendo o ano de Fiuza (2015) e Côrtes (2015).

2) Estudos que investigaram os saberes e práticas dos professores; e

Foram classificadas 7 pesquisas, que são: Kichow (2009), Esteves (2009), Miola (2011), Pereira (2011), Alves (2014), Lima (2014) e Rogeri (2015). Essa foi a classificação com maior índice de incidência. Em que cabe destacar que as pesquisas de Kichow (2009), Esteves (2009), além de serem no mesmo ano, foram na mesma instituição UFMS, do mesmo PPG de Educação Matemática e com orientadores diferentes, Dr. Luiz Carlos Pais e Dr ${ }^{a}$ Neusa Maria Marques de Souza, respectivamente.

Ainda, pode ser percebido no QUADRO 1 que não houve autores que continuaram suas investigações de mestrado no doutorado. Também não há pesquisadores que orientaram mais de uma pesquisa nesse escopo. Diante de tal fato, pode-se indicar a falta de lócus ou grupos de pesquisas que investiguem de modo mais aprofundado sobre formação de professor em relação aos números decimais.

\section{SOBRE O TEOR DAS TESES OU DISERTAÇÕES}

Nessa seção são apresentados os dados dos estudos levantados, que são: objetivo(s) da pesquisa, procedimento metodológico utilizado e resultado obtido. Fez-se questão de deixar integralmente o(s) objetivo(s) apresentado(s) pelos autores, visto que uma sutil mudança no texto pode mudar sua especificidade. 
A primeira pesquisa encontrada, em relação à ordem cronológica, foi a dissertação de Jucá (2008, p. 27) que objetivou "[...] investigar se uma sequência didática desenvolvida por um conjunto de atividades com a calculadora e jogos apresenta resultados satisfatórios no ensino das operações fundamentais com os números decimais". A autora desenvolveu uma sequência didática à luz da teoria das situações didáticas de Brousseau e utilizou a Engenharia Didática para validá-la. Por fim, a análise dos resultados mostrou que houve aumento significativo na compreensão das regras dos números decimais e, principalmente, nas operações de adição e subtração. Assim, concluiu que a sequência didática aplicada favoreceu o aprendizado das regras das operações com números decimais.

Durante o mestrado, Kichow (2009, p. 21) realizou uma pesquisa que teve como objetivo "[...] investigar e descrever os procedimentos didáticos relativos ao estudo dos números racionais utilizados por professores que atuam em nível de sexto e sétimo ano do ensino fundamental". O autor embasou-se na teoria antropológica do didático, proposta por Yves Chevallard e indica que dados utilizados na parte experimental foram coletados por meio da observação direta de aulas ministradas, da análise de três cadernos de estudantes e de entrevistas com os professores. Os discursos e práticas realizadas por meio de explanações orais e uso de textos, principalmente os anotados na lousa, foram analisados com base na abordagem fenomenológica. Com isso, como resultado, o pesquisador constatou que as práticas efetivas na aula são as que valorizam a utilização das técnicas, o que provavelmente ocorra em função da vivência desse professor no período em que era estudante na educação básica.

Em seu curso de mestrado, Esteves (2009, p. 69) objetivou "[...] investigar os conhecimentos de um grupo de professores do $5^{\circ}$ ano do Ensino Fundamental sobre números decimais e a relação desses conhecimentos com sua prática pedagógica". Foram realizadas observações das aulas e cinco sessões de atividade com os professores sobre números decimais que envolveram o conceito de números racionais, as operações com números decimais e as relações estabelecidas entre números decimais; numeração 
decimal; sistemas de medidas; e sistema monetário. Para obtenção dos dados, foram realizadas entrevistas semiestruturadas e análise de documentos, como cadernos de alguns estudantes e caderno de plano dos professores, com suporte da Análise de Conteúdo. Os resultados mostraram a existência de lacunas na estrutura cognitiva específica sobre números decimais desses professores, as quais interferem em sua prática pedagógica e tendem a influenciar a forma como organizam o processo de ensino e aprendizagem dos números decimais em sala de aula.

Miola (2011, p. 14), em sua dissertação, objetivou "[...] analisar as reflexões sobre as práticas docentes e os conhecimentos construídos e mobilizados por um grupo de professores durante a realização de encontros visando o ensino de números decimais no sexto ano do Ensino Fundamental". Para isso, foram realizados 6 encontros com 6 professores em que discutiram e elaboraram uma sequência de atividades com o uso de material didático manipulável. Como referência para a organização e a análise dos dados, foi utilizado o modelo teórico desenvolvido por Lee Shulman sobre a base de conhecimentos para o ensino. Assim como os resultados obtidos por Esteves (2009), os resultados revelaram lacunas nos conhecimentos dos professores participantes em relação aos números decimais. As análises ainda indicaram que os encontros contribuíram para que pudessem expor suas dúvidas, suas experiências e conhecimentos, de modo a refletir sobre a sua prática e que percebessem a necessidade dos conhecimentos específicos, pedagógicos e curricular desse conteúdo.

Pereira (2011, p. 12) realizou um estudo cujo objetivo foi "[...] investigar a contribuição do método de resolução de problemas para a compreensão das operações com números decimais". Para sua realização, foram utilizados como instrumentos de coleta de dados a observação participante registrada por meio de um diário de aula, um teste diagnóstico e documentos produzidos nas resoluções dos problemas. Então, chegou à conclusão que a aplicação do método de resolução de problemas foi válida por possibilitar a realização de um trabalho coletivo e colaborativo, além de desenvolver a autonomia na construção de seu próprio 
conhecimento. Também indicou a existência de lacunas em relação a aprendizados anteriores.

Em sua tese de doutorado, Sakay (2012, p. 27) objetivou "[...] analisar as implicações pedagógicas decorrentes de se trabalhar com os decimais antes dos fracionários" (inversão curricular). Foi uma pesquisa ativa, de cunho qualitativo, caracterizada como estudo de caso. A investigação foi realizada com envolvimento de um total de 54 alunos e 2 de seus professores. Os procedimentos e instrumentos adotados para o registro foram caderno de campo, fotografia, gravação de áudio e vídeo, questionário e tarefas resolvidas pelos estudantes. As sequências didáticas executadas para o ensino do número racional positivo na forma decimal partiram do sistema monetário brasileiro, do estudo das frações decimais e demais frações, e do estudo das medidas, principalmente as de comprimento. Como resultado, a pesquisadora diz acreditar que a prática do professor não difere da realidade da maioria das escolas brasileiras. Desse modo, existe uma possibilidade de adequação metodológica e gestão curricular de acordo com a realidade sociocultural em que a escola está inserida.

Alves (2014, p. 13), durante seu mestrado, realizou uma pesquisa com o objetivo de "[...] analisar como os números decimais [...] foram trabalhados no Ensino Fundamental II, desde a década de 1930, com enfoque principal às ideias do professor Euclides de Medeiros Guimarães Roxo, até o início do Movimento da Matemática Moderna". Como percurso metodológico a pesquisadora procurou identificar as diferenças e semelhanças no estudo desses números em livros didáticos publicados durante o período em que ocorreram as reformas Francisco Campos, Capanema e o Movimento da Matemática Moderna. Em conclusão, com base nas análises realizadas, foi possível perceber que o Movimento da Matemática Moderna apresentou algumas semelhanças com as propostas efetuadas por Euclides Roxo. De modo geral, durante o período analisado, foi constatado que a forma de abordar os números em sua representação decimal praticamente não sofreu modificações. 
Em sua dissertação, Lima (2014, p. 9) teve como objetivo "[...] compreender as relações entre professores e materiais curriculares para 0 ensino de números naturais e sistema de numeração decimal". Tratou-se de uma investigação com abordagem qualitativa, fundamentada na análise de questionários, depoimentos e áudios gravados nas aulas de quatro professoras. A pesquisadora pôde identificar a ocorrência de diferentes tipos de uso do material pelas professoras, a saber: a adaptação, a reprodução e a criação. Em certa medida, elas ora reproduzem, ora adaptam e mais raramente criam. Foi constatado que a adaptação foi frequente durante as práticas observadas e os resultados indicam que material didático deve ser objeto da formação desses profissionais, aprofundando-se tanto nos conteúdos matemáticos envolvidos, como nos conhecimentos didáticos a eles referentes.

A investigação de Fiuza $(2015$, p. 21$)$ teve o objetivo de "[...] investigar as potencialidades de uma sequência didática eletrônica como estratégia de ensino para o tema dos números decimais, integrados ao tema transversal trabalho e consumo, para $\circ 6^{\circ}$ ano do ensino fundamental". A investigação foi desenvolvida em três etapas: 1) Levantamento bibliográfico dos aspectos teóricos e didáticos da temática números decimais, investigando atividades didáticas relacionadas com o tema transversal trabalho e consumo; 2) Implementação de um ambiente virtual de investigação; 3) Experimento real. O conceito de melhor desempenho foi o de situações do dia a dia em que os estudantes identificaram e reconheceram os números decimais no cotidiano. Por fim, com base no desempenho dos estudantes, pode-se perceber que o estudo da utilização da sequência foi positivo para a construção dos conceitos.

A tese da pesquisadora Rogeri $(2015$, p. 42) teve o objetivo de "[...] investigar a ampliação da base de conhecimentos de um grupo de professores dos anos iniciais do ensino fundamental para o ensino de números racionais, sobretudo a representação decimal". Isso mediante uma formação continuada, em que os pressupostos são reflexões compartilhadas em relação às práticas docentes e dificuldades da aprendizagem de 
conceitos relativos ao tema. O estudo ocorreu em 2 fases: 1) Aplicação de questionários para identificar conhecimentos e práticas dos professores; 2) Discussão com o grupo de professores sobre situações de aprendizagem e estudos a respeito dos processos de ensino e aprendizagem dos números decimais. No tocante à formação de professores reflexivos, em um ambiente de estudo de inovações curriculares, foram utilizadas as ideias defendidas por Zeichner. Como resultado, as discussões e reflexões realizadas durante o processo formativo ampliaram a imagem conceitual e a base de conhecimentos dos professores para ensinar números racionais. Também é apontada a necessidade de haver articulações entre diferentes abordagens, estratégias e materiais para os processos de ensino e aprendizagem de números racionais, representados na forma decimal.

Durante seu mestrado, Côrtes $(2015$, p. 6) realizou um estudo que teve como objetivo "[...] buscar uma forma prazerosa de se trabalhar a matemática em sala de aula, principalmente as frações e números decimais, sem deixar de lado o rigor que a matemática exige". Para cumprir esse objetivo, o autor inicia com uma explanação de modo formal sobre a formação dos conjuntos numéricos. Em seguida, sugere uma alternativa para trabalhar frações e números decimais de modo que não seja desconexo entre si e os demais conteúdos. Como conclusão, o autor indica que o plano de ensino apresentado é uma sugestão e que cabe ao professor utilizar o seu conhecimento para encontrar o próprio caminho e o melhor modo de auxiliar os estudantes.

Essas foram todas as teses ou dissertações encontradas que estudaram, com base em alguma perspectiva, os números decimais que tiveram como foco a formação do professor que ensina matemática. Podese perceber que os estudos são bastante variados e que cada um contribui de uma forma idiossincrática com a construção desse conhecimento em específico. Seja na formação inicial ou continuada do professor ou no método utilizado com o estudante.

Quanto às palavras-chave indicadas em todas as publicações, foi contabilizado um total de 39 que perfaz uma média de 3,5 palavras. As 
frequências de cada palavra e de agrupamentos podem ser observadas no QUADRO 2.

QUADRO 2 - Palavras-chave e suas respectivas frequências unitárias e agrupadas

\begin{tabular}{|c|c|c|c|c|c|}
\hline \multirow{3}{*}{$\begin{array}{l}\text { Palavra-Chave } \\
\text { Números Decimais } \\
\text { Ensino de Decimais }\end{array}$} & \multicolumn{2}{|c|}{ Frequências } & \multirow{3}{*}{\begin{tabular}{l}
\multicolumn{1}{c}{ Palavra-Chave } \\
Sequência Didática \\
Sequência Didática Eletrônica
\end{tabular}} & \multicolumn{2}{|c|}{ Frequências } \\
\hline & 6 & \multirow{2}{*}{$7^{i}$} & & 1 & \multirow{2}{*}{$2^{v}$} \\
\hline & 1 & & & 1 & \\
\hline \multirow{2}{*}{$\begin{array}{l}\text { Conhecimento Matemático } \\
\text { para o Ensino }\end{array}$} & \multirow{2}{*}{1} & \multirow{7}{*}{$6 i i$} & Calculadora & 1 & 1 \\
\hline & & & Frações & 1 & 1 \\
\hline Conhecimentos dos professores & 2 & & Ensino e Aprendizagem & 1 & 1 \\
\hline Práticas Docentes & 1 & & Ensino Fundamental & 1 & 1 \\
\hline Formação de Professores & 1 & & Euclides Roxo & 1 & 1 \\
\hline \multirow{2}{*}{$\begin{array}{l}\text { Formação de Professores de } \\
\text { Matemática }\end{array}$} & \multirow{2}{*}{1} & & Formação e Demonstrações & 1 & 1 \\
\hline & & & \multirow{2}{*}{$\begin{array}{l}\text { Formalização dos Conjuntos } \\
\text { Numéricos }\end{array}$} & \multirow{2}{*}{1} & \multirow{2}{*}{1} \\
\hline Educação Matemática & 4 & 4 & & & \\
\hline Números Racionais & 2 & \multirow{3}{*}{$4 \mathrm{iii}$} & Livro Didático & 1 & 1 \\
\hline Número Racional & 1 & & Números Naturais & 1 & 1 \\
\hline Ensino do Número Racional & 1 & & Reflexões & 1 & 1 \\
\hline Currículo & 1 & \multirow{3}{*}{3 iv } & SIENA & 1 & 1 \\
\hline Materiais Curriculares & 1 & & Teoria Antropológica do Didático & 1 & 1 \\
\hline Ensino e Gestão Curricular & 1 & & Trabalho e Consumo & 1 & 1 \\
\hline
\end{tabular}

Fonte: Repositórios das instituições onde os trabalhos foram publicados.

Notas: As palavras-chave foram agrupadas conforme afinidades: i) números decimais; ii) professores; iii) números racionais; iv) currículo; e v) sequência didática.

No QUADRO 2 pode ser percebida a predominância das palavraschave que dizem respeito aos professores ou aos números decimais, 13 no total. Ou seja, uma a cada três palavras-chave tem relação com professores ou com números decimais. Ainda há grande frequência em Educação Matemática e no agrupamento números racionais. As palavras-chave de frequência unitária, também em um total de 13, são termos que correspondem à especificidade de cada investigação. Desse modo, os dados vão de encontro ao elucidado por Miguéis et al. (2013) ao afirmar que as palavras indicam a abrangência de um assunto e seus conceitos principais. 


\section{SOBRE AS REFERÊNCIAS UTILIZADAS NAS TESES OU DISERTAÇÕES}

\section{Frequência de tipos e período de publicação utilizada como referência}

A primeira referência é datada de 1920 e a última de 2015 (ano dos últimos itens do QUADRO 1) e, devido a esse parâmetro temporal, foi necessária a classificação em períodos longitudinalmente diversos, pois o primeiro constou 6 décadas, devido não haver quantidade expressiva de publicações contabilizada por década nesse período, e a última classificação constou somente de 5 anos por ser uma década ainda corrente. Os dados podem ser observados na TABELA 3.

TABELA 3 - Tipos de publicação classificados conforme o período

\begin{tabular}{ccccccccc}
\hline Período & Livro & Artigo & Capítulo & Dissertação & Evento & Tese & Outro vi & Total \\
\hline $1920-1979$ & 10 & 1 & 1 & 0 & 0 & 0 & 1 & $\mathbf{1 3}$ \\
$1980-1989$ & 18 & 21 & 6 & 0 & 2 & 0 & 0 & $\mathbf{4 7}$ \\
$1990-1999$ & 78 & 35 & 30 & 2 & 8 & 3 & 6 & $\mathbf{1 6 2}$ \\
$2000-2009$ & 134 & 81 & 37 & 43 & 24 & 26 & 15 & $\mathbf{3 6 0}$ \\
$2010-2015$ & 30 & 8 & 2 & 9 & 11 & 8 & 3 & $\mathbf{7 1}$ \\
\hline Total & $\mathbf{2 7 0}$ & $\mathbf{1 4 6}$ & $\mathbf{7 6}$ & $\mathbf{5 4}$ & $\mathbf{4 5}$ & $\mathbf{3 7}$ & $\mathbf{2 5}$ & $\mathbf{6 5 3}$ \\
\hline
\end{tabular}

Fonte: Repositórios das instituições onde os trabalhos foram publicados.

Notas: vi) nessa classificação estão consultas a sites, textos particulares, entrevistas e outros tipos de publicação; vii) o total ficou 3 unidades menor devido haver 3 referências do tipo "Outro" sem serem datadas.

O período de publicação que concentra a maior quantidade consultada é a década de 2000 a 2009, em que possui mais da metade de todas publicações $(55,13 \%)$. Já o tipo de publicação que teve maior frequência foi o livro (41,35\%), seguido dos artigos (22,36\%). Ainda, cabe destacar que teses ou dissertações só começaram a ser utilizadas na década de 1990, ambas mais precisamente em 19944.

Para interpretação de crescimento e decrescimento dos tipos de publicação consultada no decorrer do tempo, é apresentada a FIGURA 1.

\footnotetext{
${ }^{4}$ Tese: Developing realistic mathematics education de Koeno Gravemeijer em 1994. Dissertação: Fundamentos da Educação Matemática na prática pedagógica do cotidiano escolar: o jogo em questão de Neusa Maria Marques Souza em 1994.
}

Revista Êxitos, Santarém/PA, Vol. 9, № 4, p. 606 - 634, Out/Dez 2019. 
FIGURA 1 - Relação dos tipos de publicação conforme o período

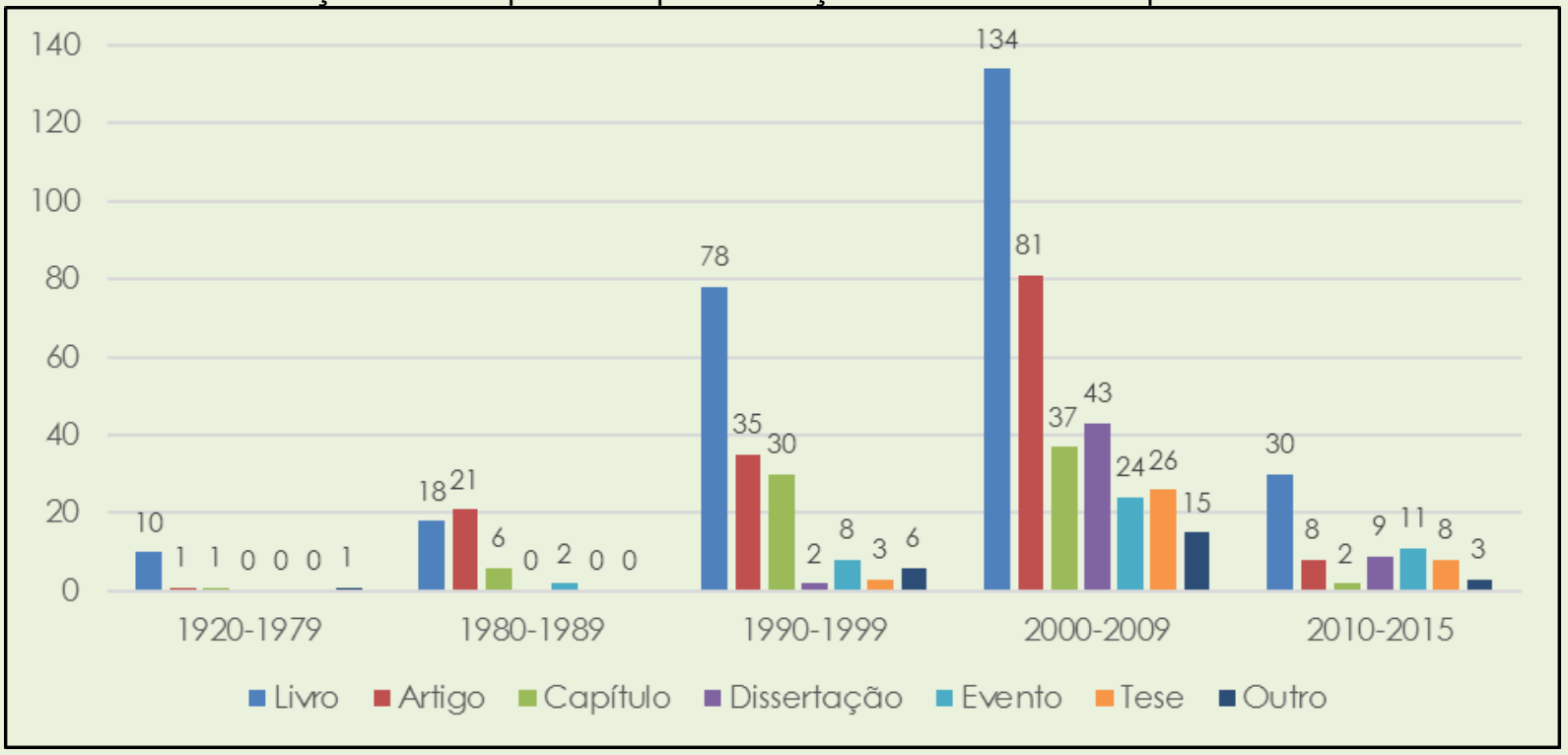

Fonte: Repositórios das instituições onde os trabalhos foram publicados.

Apesar da ampla utilização de referências de livros nas teses ou dissertações analisadas, publicados na década de 1980, houve mais artigos que livros. Tal fato pode ser evidenciado devido autores, como Guy Brousseau, terem pesquisado sobre números decimais nessa época e ter muitos dos resultados de suas pesquisas publicadas em periódicos científicos.

Macias-Chapula (1998) indica que a principal limitação de identificar a produtividade científica é a cobertura da maioria das bases de dados que não incluem livros, capítulos de livros, teses, dissertações e não incorpora a chamada 'literatura cinzenta', que são relatórios técnicos, conferências, notas técnicas, entre outros. O que pode evidenciar o não aparecimento desse tipo de publicação na investigação, visto que a classe "Outros" é formada por publicações como páginas institucionais, sites e outros obtidos/consultados por meios digitais.

De acordo com o constatado por Mueller (2005) ao indicar que pesquisadores de diferentes áreas têm preferências próprias, em relação à investigação em que seus dados são expostos na FIGURA 1, pode-se perceber que há preferência dos pesquisadores por livros, mesmo com grande divulgação de artigos por meio digital. Ainda há os capítulos de 
livros, que são partes integrantes de livros, que também são amplamente utilizados.

\section{Autores de referência com maior frequência}

Os autores não coorporativos e coorporativos, utilizados como referências em cada uma das pesquisas são importante elo entre o que já se estudou, o que se pretende investigar e os referenciais teóricos utilizados (RODRIGUES, 1982). Ao considerar até o terceiro autor, nas teses ou dissertações investigadas foram citados 459 autores, nas quais 303 autores foram citados uma única vez, 73 foram citados duas vezes e 39 foram citados três vezes. Os demais 44 autores são apresentados no QUADRO 3, que mostra a relação de frequência de autores citados mais de 3 vezes nas teses ou dissertações investigadas.

QUADRO 3 - Autores das referências com frequência igual ou maior que 4

\begin{tabular}{|c|c|c|c|}
\hline Autor & Frequência & Autor & Frequência \\
\hline BRASIL & 29 & ZEICHNER, Kenneth & 5 \\
\hline PONTE, João Pedro da & 26 & PIETROPAOLO, RUY & 5 \\
\hline SÃO PAULO (ESTADO) & 11 & PAIS, Luiz Carlos & 5 \\
\hline SHULMAN, Lee & 11 & BOSCH, Marianna & 5 \\
\hline VALENTE, Wagner Rodrigues & 11 & IEZZI, Gelson & 4 \\
\hline BROUSSEAU, GUY & 11 & MOREIRA, Plínio Cavalcanti & 4 \\
\hline DANTE, Luiz Roberto & 8 & BICUDO, Maria Viggiani & 4 \\
\hline FIORENTINI, Dario & 8 & BIGODE, Antonio José Lopes & 4 \\
\hline SERRAZINA, Lurdes & 8 & BITTAR, Marilena & 4 \\
\hline TARDIF, Maurice & 8 & FONSECA, Fábio Luiz & 4 \\
\hline CUNHA, Micheline & 7 & GARCÍA, Carlos Marcelo & 4 \\
\hline CHEVALLARD, Yves & 7 & GIOVANNI, José Ruy & 4 \\
\hline SACRISTAN, Gimeno & 7 & POST, Thomas & 4 \\
\hline PIRES, Célia Maria Carolino & 7 & RIBEIRO, Carlos Miguel & 4 \\
\hline GROENWALD, Claudia Lisete & 6 & SANTOS, Vinício de Macedo & 4 \\
\hline PADOVAN, Daniela Maria & 6 & VYGOTSKY, Lev Semyonovich & 4 \\
\hline NACARATO, Adair Mendes & 6 & WILSON, Suzanne & 4 \\
\hline MUNIZ, Cristiano Alberto & 6 & MAGALHÃES, José Luiz & 4 \\
\hline BEHR, Merlyn & 5 & PÉREZ, Julia Centeno & 4 \\
\hline MIZUKAMI, Maria Nicoletti & 5 & PIAGET, Jean & 4 \\
\hline
\end{tabular}




\begin{tabular}{|l|l|l|l|}
\hline MONTEIRO, Maria Cecília & 5 & OLIVEIRA, Hélia & 4 \\
\hline GIOVANNI JÚNIOR, José Ruy & 5 & CURI, Edda & 4 \\
\hline
\end{tabular}

Fonte: Repositórios das instituições onde os trabalhos foram publicados.

Um fator relevante a ser considerado é a nacionalidade dos autores que serviram como referência para as teses ou dissertações, foco da investigação mostrados no QUADRO 4. Foram encontradas 8 nacionalidades para os autores, que são, em ordem de frequência, Brasil, Estados Unidos, Portugal, Espanha, França, Canadá, Rússia (atual Bielorrússia) e Suíça. Conforme indicado por Vergara e Pinto (2001), as referências bibliográficas utilizadas podem ser indicadores da importância por ele atribuída à produção científica e ao contexto brasileiro, também serem indicadores do seu condicionamento por outras culturas que não a brasileira.

O Brasil foi o país com maior frequência, com um total de 26 autores, os 18 autores estrangeiros podem ser observados no QUADRO 4, em que cabe destacar que não foi levado em consideração o idioma em que houve a publicação e sim a nacionalidade do autor, portanto a existência desses autores estrangeiros não implica que as publicações eram em outro idioma que não o português, pois podem ser publicações traduzidas para esse idioma.

QUADRO 4 - Autores estrangeiros indicados nas referências com frequência maior ou igual a 4

\begin{tabular}{|c|c|c|c|c|c|}
\hline \multirow{5}{*}{$\begin{array}{l}\text { Estados } \\
\text { Unidos }\end{array}$} & SHULMAN, Lee & \multirow{4}{*}{5} & \multirow{4}{*}{ Espanha } & SACRISTAN, Gimeno & \multirow{4}{*}{4} \\
\hline & BEHR, Merlyn & & & $\mathrm{BOSCH}$, Marianna & \\
\hline & ZEICHNER, Kenneth & & & GARCÍA, Carlos Marcelo & \\
\hline & POST, Thomas & & & PÉREZ, Julia Centeno & \\
\hline & WILSON, Suzanne & & \multirow{2}{*}{ França } & BROUSSEAU, GUY & \\
\hline \multirow{4}{*}{ Portugal } & PONTE, João Pedro da & & & CHEVALLARD, Yves & 2 \\
\hline & SERRAZINA, Lurdes & \multirow{3}{*}{4} & Canadá & TARDIF, Maurice & 1 \\
\hline & RIBEIRO, Carlos Miguel & & Rússia & VYGOTSKY, Lev Semyonovich & 1 \\
\hline & OLIVEIRA, Hélia & & Suíça & PIAGET, Jean & 1 \\
\hline
\end{tabular}

Fonte: Repositórios das instituições onde os trabalhos foram publicados.

De volta aos dados apresentados no QUADRO 3, há de se destacar a importância das bases legais nas investigações, visto que o autor mais citado é o coorporativo Brasil, constituído predominantemente pelos Parâmetros 
Curriculares Nacionais e dispositivos legais como a Lei de Diretrizes e Bases da Educação Nacional (Lei no 9.394/1996), e o coorporativo São Paulo (Estado) que é o terceiro mais citado, também é constituído por parâmetros e aspectos legais. Isso mostra a preocupação que os autores das teses ou dissertações tiveram em suas investigações quanto aos aspectos legais.

Dentre os autores não coorporativos com maior quantidade de referências, o mais indicado foi João Pedro da Ponte. Este autor se destaca pela quantidade e diversidade de publicações citadas de sua autoria e coautoria, ao todo, 18 obras distintas em que os assuntos variam entre currículo, formação profissional de professores e aprendizagem dos estudantes.

Em seguida ficam 3 autores com 11 frequências cada, Lee Shulman, Wagner Rodrigues Valente e Guy Brousseau. Em que, respectivamente, 0 primeiro foi distribuído em 4 publicações, o segundo e o terceiro em 9 publicações. O que cabe destacar nesses 3 autores são suas linhas de pesquisas. Lee Shulman focaliza a formação de professores, Wagner Rodrigues Valente, a história do ensino de matemática com base nos aspectos da formação de professores, materiais didáticos e movimentos históricos, e Guy Brousseau pelas contribuições em didática da matemática ${ }^{5}$ e estudos sobre questões que envolvem os números decimais.

Os livros didáticos também ganharam destaque nas teses ou dissertações investigadas, visto que o livro didático tem se constituído como um dos principais instrumentos utilizados no processo de ensino. Assim, as investigações ou seções delas foram dedicadas a esse material didático. $O$ destaque em frequência fica com José Ruy Giovanni Júnior que obteve 5 frequências, seguido de Roberto Dante que obteve frequência 8, em que das 5 publicações somente 2 são de livros didáticos que totalizam 4 frequências, Gelzon lezzi e José Ruy Giovanni que obtiveram 4 itens de frequência cada em livros didáticos.

\footnotetext{
${ }^{5}$ Nesse texto, "didática da matemática" se refere à didática da matemática francesa. Caso contrário, será ressalvado quando houver necessidade.
}

Revista Êxitos, Santarém/PA, Vol. 9, № 4, p. 606 - 634, Out/Dez 2019. 
Também houve autores que representam outros segmentos, como Gimeno Sacristán e Ruy Pietropaolo que têm estudos publicados como foco no currículo, Maurice Tardif e Dario Fiorentini em formação de professores, Luiz Carlos Pais e Marilena Bittar em didática da matemática, e Jean Piaget e Lev Semyonovich Vygotsky que são alicerces da teoria construtivista.

Já para as teses ou dissertações como referência, são destacadas a de Micheline Cunha e a de Daniela Maria Padovan que obtiveram frequência 7 e 5, respectivamente. Para essa segunda autora, também foi contabilizada frequência 1 para um livro, o que perfaz a frequência 6 apresentada no QUADRO 3.

\section{Publicações referências com maior frequência}

Cada referência bibliográfica utilizada por um autor, ou pelos autores, revelam os suportes teóricos de argumentação utilizados e podem ser indicadores da importância por ele atribuída à produção científica (VERGARA; PINTO, 2001). Nas publicações foco da investigação, foram contabilizadas 537 publicações utilizadas como referência, em que 456 dessas publicações tiveram frequência 1, 58 tiveram frequência 2 e as demais 22 que tiveram frequência de 3 a 7 estão dispostos no QUADRO 5.

QUADRO 5 - Publicações utilizadas como referência com frequência de 3 a 7

\begin{tabular}{|c|c|c|}
\hline $\begin{array}{c}\text { Autor } \\
\text { principal }\end{array}$ & Publicação & Frequência \\
\hline $\begin{array}{l}\text { CUNHA, } \\
\text { Micheline }\end{array}$ & $\begin{array}{l}\text { A quebra da unidade e o número decimal: Um estudo } \\
\text { diagnóstico nas primeiras séries do Ensino Fundamental }\end{array}$ & 7 \\
\hline BRASIL & $\begin{array}{l}\text { Parâmetros Curriculares Nacionais: Matemática }\left(3^{\circ} \text { e } 4^{\circ}\right. \\
\text { Ciclos) }\end{array}$ & 6 \\
\hline $\begin{array}{l}\text { PADOVAN, } \\
\text { Daniela Maria }\end{array}$ & Números decimais: o erro como caminho & 5 \\
\hline $\begin{array}{l}\text { PEREZ, Julia } \\
\text { Centeno }\end{array}$ & Números decimales: ¿PPor qué? ¿ Para qué? & 5 \\
\hline BRASIL & $\begin{array}{l}\text { Parâmetros Curriculares Nacionais: Matemática }\left(1^{\circ} \text { e } 2^{\circ}\right. \\
\text { Ciclos) }\end{array}$ & 5 \\
\hline $\begin{array}{l}\text { ZUNINO, Delia } \\
\text { Lerner }\end{array}$ & A matemática na escola: aqui e agora & 4 \\
\hline $\begin{array}{l}\text { BITTAR, } \\
\text { Marilena }\end{array}$ & $\begin{array}{l}\text { Fundamentos e Metodologia de Matemática para os Ciclos } \\
\text { Iniciais do Ensino Fundamental }\end{array}$ & 4 \\
\hline $\begin{array}{l}\text { PONTE, João } \\
\text { Pedro da }\end{array}$ & Números e Álgebra no Currículo Escolar & 4 \\
\hline
\end{tabular}




\begin{tabular}{|c|c|c|}
\hline $\begin{array}{l}\text { TARDIF, } \\
\text { Maurice }\end{array}$ & Saberes docentes e formação profissional & 4 \\
\hline $\begin{array}{l}\text { SHULMAN, } \\
\text { Lee }\end{array}$ & Those Who Understand: Knowledge Growth in Teaching & 4 \\
\hline $\begin{array}{l}\text { ABRANTES, } \\
\text { Paulo }\end{array}$ & A Matemática na Educação Básica & 3 \\
\hline $\begin{array}{l}\text { CHEVALLARD, } \\
\text { Yves }\end{array}$ & $\begin{array}{l}\text { Estudar Matemáticas: o elo perdido entre o ensino e a } \\
\text { aprendizagem }\end{array}$ & 3 \\
\hline $\begin{array}{l}\text { BOYER, Carl } \\
\text { Benjamin }\end{array}$ & História da Matemática & 3 \\
\hline $\begin{array}{l}\text { CHERVEL, } \\
\text { André }\end{array}$ & $\begin{array}{l}\text { História das disciplinas escolares: reflexões sobre um campo } \\
\text { de pesquisa }\end{array}$ & 3 \\
\hline $\begin{array}{l}\text { IFRAH, } \\
\text { Georges }\end{array}$ & História Universal dos Algarismos & 3 \\
\hline $\begin{array}{l}\text { MARCHESI, } \\
\text { Armando }\end{array}$ & $\begin{array}{l}\text { Inversão de mão na rua dos racionais: dos números com } \\
\text { vírgula para os fracionários }\end{array}$ & 3 \\
\hline $\begin{array}{l}\text { SILVA, Maria } \\
\text { Ferreira da }\end{array}$ & $\begin{array}{l}\text { Investigando saberes de professores do Ensino Fundamental } \\
\text { com enfoque em números fracionários para a quinta série }\end{array}$ & 3 \\
\hline $\begin{array}{l}\text { SHULMAN, } \\
\text { Lee }\end{array}$ & Knowledge and teaching: foundations of the new reform & 3 \\
\hline IEZZI, Gelson & Matemática e Realidade & 3 \\
\hline $\begin{array}{l}\text { SILVA, } \\
\text { Valdenice da }\end{array}$ & $\begin{array}{l}\text { Números decimais: no que os saberes de adultos diferem } \\
\text { dos de criança? }\end{array}$ & 3 \\
\hline $\begin{array}{l}\text { SACRISTAN, } \\
\text { Gimeno }\end{array}$ & O currículo: uma reflexão sobre a prática & 3 \\
\hline $\begin{array}{l}\text { DANTE, Luiz } \\
\text { Roberto }\end{array}$ & Tudo é matemática & 3 \\
\hline
\end{tabular}

Fonte: Repositórios das instituições onde os trabalhos foram publicados.

Dos títulos das publicações utilizadas como referência com frequência maior ou igual a 3, cabe novamente destacar as investigações de stricto sensu realizadas Micheline Cunha e Daniela Maria Padovan que obtiveram frequência 7 e 5, respectivamente. Esse dado significa que essas investigações serviram de referência e foram citadas em 63,64\% e 45,45\%, nessa ordem, das 11 teses ou dissertações que foram foco da investigação.

Além da dissertação de Micheline Cunha ter a maior frequência e a de Daniela Maria Padovan ter a terceira maior, figurando juntamente com o livro de Julia Centeno Perez e os Parâmetros Curriculares Nacionais de primeiro a quinto ano, do autor coorporativo Brasil, ampliando o grupo de investigações de stricto sensu utilizadas como referências, tem-se a dissertação de Valdenice da Silva e a tese de Maria Ferreira da Silva, ambas com frequência 3. 
Uma situação a ser destacada é a presença expressiva dos Parâmetros Curriculares Nacionais, tanto do primeiro a quinto ano quanto do sexto ao nono ano, que sugere a preocupação com as orientações do que é indicado nessas duas publicações. Mesmo sendo publicações de 1997 e 1998, as teses ou dissertações que foram publicadas de 2008 a 2015 ainda fazem uso delas.

São confirmadas, em relação ao QUADRO 5, as preocupações com o currículo por meio de Gimeno Sacristán, livro didático por meio de Roberto Dante e Gelson lezzi, formação de professores por meio de Maurice Tardif e didática da matemática por meio de Marilena Bittar. Ainda, apesar de João Pedro da Ponte ter tido frequência 26 (QUADRO 3) teve somente uma publicação que cumpre o critério para constar no QUADRO 5. As demais 17 publicações utilizadas como referência obtiveram frequência menor que 3.

A novidade da frequência das publicações (QUADRO 5) em relação à frequência dos autores (QUADRO 3) é o aparecimento de 2 publicações em livro que se referem à história da matemática. Os livros de Carl Benjamin Boyer e Georges Ifrah, ambos com frequência 3, trazem à tona uma nova vertente que não pôde ser percebida na frequência dos autores, que é a preocupação com os aspectos históricos dos números decimais.

\section{CONSIDERAÇÕES FINAIS}

Ao considerar os estudos, ainda preliminares, da tese de doutoramento do autor que trata sobre os números decimais, percebeu-se que é de grande valia pesquisar sobre publicações fruto de investigações em cursos de mestrado ou doutorado que trate do tema. Especialmente no que tange à formação de professores que ensinam matemática. Durante a realização da investigação, foi possível perceber o panorama epistemológico diversificado que existe quando se trata dessas investigações.

Com fundamento nessa investigação realizada, foi possível realizar um estudo sobre as teses ou dissertações que cumpriam o escopo, das palavraschave e das publicações utilizadas como referências. Foi realizado um mapeamento e constatada a variedade de objetivos, metodologias e 
resultados. Ainda, e mais profundamente, analisados os principais pressupostos teóricos que embasaram as investigações de mestrado ou doutorado por meio de suas referências, em que foram considerados ano, tipo, autor e título dessas.

Desse modo, considera-se que a questão norteadora foi respondida e os objetivos propostos na elaboração dessa investigação foram atingidos. Ademais, acredita-se que essa publicação possa contribuir com pesquisadores que queiram futuramente pesquisar sobre formação de professores que ensinam matemática no que se refere aos números decimais. Pois, como a investigação não esgota tudo que já foi produzido sobre o tema, já poderão iniciar suas investigações a partir de resultados apresentados nessa publicação, para ampliar suas inferências e possíveis generalizações.

\section{REFERÊNCIAS}

ALVES, R. B. Os números em sua representação decimal: de Euclides Roxo ao Movimento da Matemática Moderna. 2014. 128. São Paulo: Dissertação (Mestrado em Educação Matemática) - Universidade Anhanguera de São Paulo, São Paulo, 2014. Disponível em: <https://s3.amazonaws.com/pgsskrotondissertacoes/7a9eded51ala3aa295e6bd189c89fd63.pdf>. Acesso em: 10 set. 2017.

BARDIN, L. Análise de conteúdo. Tradução de Luís Antero Reta; Augusto Pinheiro. Lisboa: Edições 70, 2011.

BERTERO, C. O.; CALDAS, M. P.; WOOD JR, T. Produção científica em administração de empresas: provocações, insinuações e contribuições para um debate local. Revista de Administração Contemporânea, Curitiba, v. 3, n. 1, p. 147-178, 1999. Disponível em: <http://www.scielo.br/pdf/rac/v3n1/v3nla09.pdf>. Acesso em: 16 jul. 2018.

CÔRTES, C. A. Formalização dos conjuntos numéricos: contribuição para o ensino de frações e números decimais. 2015. 67 f. São José do Rio Preto: Dissertação (Mestrado Profssional em Matemática em Rede Nacional) Universidade Estadual Paulista Julio Mesquisa Filho, José do Rio Preto, 2015. Disponível em:

<https://repositorio.unesp.br/bitstream/handle/1 1449/127750/000845945.pdf?s equence $=1$ \&isAllowed $=y>$. Acesso em: 10 set. 2017. 
ESTEVES, A. K. Números decimais na escola fundamental: interações entre os conhecimentos de um grupo de professores e a relação com sua prática pedagógica. 2009. 152 f. Campo Grande: Dissertação (Mestrado em Educação Matemática) - Universidade Federal do Mato Grosso do Sul, Campo Grande, 2009. Disponível em:

<https://sistemas.ufms.br/sigpos/portal/trabalhos/download/1802/cursold:91> . Acesso em: 10 set. 2017.

FIUZA, R. P. Números decimais e o tema transversal trabalho e consumo: um experimento utilizando uma sequência didática eletrônica. 2015. 245 f. Canoas: Dissertação (Mestrado em Ensino de Ciências e Matemática) Universidade Luterana do Brasil, Canoas, 2015. Disponível em:

<https://sucupira.capes.gov.br/sucupira/public/consultas/coleta/trabalhoCo nclusao/viewTrabalhoConclusao.jsf?popup=true\&id_trabalho=2927699>.

Acesso em: 10 set. 2017.

JUCÁ, R. de S. Uma sequência didática para o ensino das operações com os números decimais. 2008. 192 f. Belém: Dissertação (Mestrado em Educação) - Universidade do Estado do Pará, Belém, 2008. Disponível em:

<http://ccse.vepa.br/mestradoeducacao/wp-

content/uploads/dissertacoes/02/rosineide_de_souza_juca.pdf>. Acesso em: 10 set. 2017.

$\mathrm{KICHOW}, \mathrm{I}$. Vr. Procedimentos didáticos relativos ao ensino de números racionais em nível de sexto e sétimo anos do ensino fundamental. 2009. 116 f. Campo Grande: Dissertação (Mestrado em Educação Matemática), Universidade Federal de Mato Grosso do Sul, Campo Grande, 2009. Disponível em: <http://grupoddmat.pro.br/index.php/kichow-i-vprocedimentos-didaticos-relativos-ao-ensino-de-numeros-racionais-em-nivelde-sexto-e-setimo-anos-do-ensino-fundamental-2009-116f-dissertacaomestrado-em-educacao-matematica-univer/>. Acesso em: 10 set. 2017.

LIMA, S. F. de. Relações entre professores e materiais curriculares no ensino de números naturais e sistema de numeração decimal. 2014. 215 f. São Paulo: Dissertação (Mestrado Profissional em Ensino de Matemática) Pontíficia Universidade Católica de São Paulo, 2014. Disponível em: <https://sucupira.capes.gov.br/sucupira/public/consultas/coleta/trabalhoCo nclusao/viewTrabalhoConclusao.jsf?popup=true\&id_trabalho=1705740>. Acesso em: 10 set. 2017.

LOIOLA, E.; BASTOS, A. V. B. A produção acadêmica sobre Aprendizagem Organizacional no Brasil. Revista de Administração Contemporânea, Curitiba, v. 7, n. 3, p. 181-201, 2003. Disponível em: <http://www.scielo.br/pdf/rac/v7n3/v7n3a10.pdf>. Acesso em: 15 jul. 2018.

LOPES, T. B.; SÁ, P. F. de. Levantamento da produção acadêmica em teses e dissertações brasileiras sobre ensino e aprendizagem de números decimais

Revista Êxitos, Santarém/PA, Vol. 9, № 4, p. 606 - 634, Out/Dez 2019. 
no período de 1995 a 2015 . Revista de ensino de Ciências e Matemática (REnCiMa), v. 9, n. 4, 2018. No prelo.

MACIAS-CHAPULA, C. A. O papel da informetria e da cienciometria e sua perspectiva nacional e internacional. Ciência da informação, v. 27, n. 2, p. 134-140, 1998. Disponível em:

<http://www.scielo.br/pdf/\%0D/ci/v27n2/macias.pdf>. Acesso em: 16 jul. 2018.

MIGUÉlS, A. et al. A importância das palavras-chave dos artigos científicos da área das Ciências Farmacêuticas, depositados no Estudo Geral: estudo comparativo com os termos atribuídos na MEDLINE. InCID: Revista de Ciência da Informação e Documentação, v. 4, n. 2, p. 112-125, 2013. Disponível em: <http://www.revistas.usp.br/incid/article/view/69284>. Acesso em: 17 jul. 2018.

MIOLA, A. F. de S. Uma análise de reflexões e de conhecimentos construídos e mobilizados por um grupo de professores no ensino de números decimais para o sexto ano do ensino fundamental. 2011. 148 f. Campo Grande:

Dissertação (Mestrado em Educação Matemática) - Universidade Federal de Mato Grosso do Sul, Campo Grande, 2011. Disponível em:

<https://sistemas.ufms.br/sigpos/portal/trabalhos/download/1825/cursold:91> . Acesso em: 10 set. 2017.

MUELLER, S. P. M. A publicação da ciência: áreas científicas e seus canais preferenciais. DataGramaZero - Revista de Ciência da Informação, v. 6, n. 1, p. 1-12, 2005. Disponível em: <http://repositorio.unb.br/bitstream/10482/980/2/ARTIGO_PublicacaoCiencia .pdf>. Acesso em: 15 jul. 2018.

PEREIRA, L. da Cás. Ensino e aprendizagem das operações com números decimais através da resolução de problemas no ensino fundamental. 2011. 89 f. Santa Maria: Dissertação (Mestrado Profissionalizante em Ensino de Física e de Matemática) - Centro Universitário Franciscano de Santa Maria, 2011. Disponível em:

<http://tede.unifra.br/tde_busca/arquivo.php?codArquivo=183>. Acesso em: 10 set. 2017.

RODRIGUES, M. da P. L. Citações nas dissertações de mestrado em ciência da informação. Ciência da Informação, v. 11, n. 1, p. 35-61, 1982. Disponível em: <http://revista.ibict.br/ciinf/article/view/177/177>. Acesso em: 15 jul. 2018.

ROGERI, N. K. de O. Conhecimentos de professores dos anos iniciais para o ensino dos números racionais em sua representação decimal. 2015. 287 f. São Paulo: Tese (Doutorado em Educação Matemática) - Universidade Anhanguera de São Paulo, São Paulo, 2015. Disponível em: 
<https://sucupira.capes.gov.br/sucupira/public/consultas/coleta/trabalhoCo nclusao/viewTrabalhoConclusao.jsf?popup=true\&id_trabalho=2759233>. Acesso em: 10 set. 2017.

SAKAY, L. Ensino e aprendizagem do número racional positivo na forma decimal: análise de uma experiência de inversão curricular. 2012. 327 f. Brasília: Tese (Doutorado em Educação) - Universidade de Brasília, Brasília, 2012. Disponível em: <http://repositorio.unb.br/handle/10482/12024>. Acesso em: 10 set. 2017.

VERGARA, S. C.; PINTO, M. C. S.. Referências teóricas em análise organizacional: um estudo das nacionalidades dos autores referenciados na literatura brasileira. Revista de Administração Contemporânea, Curitiba, v. 5, n. Edição especial, p. 103-121, 2001. Disponível em: <http://www.scielo.br/pdf/rac/v5nspe/v5nspea06.pdf>. Acesso em: 15 jul. 2018.

Recebido em: 09 de agosto de 2018 Aprovado em: 15 de maio de 2019 